\title{
CORRELATION OF IODINE SYMPORTER EXPRESSION IN HIGHLY AND LOW MALIGNANT CELL LINES OF HUMAN BREAST CANCER DIFFERED IN THEIR SENSITIVITY TO DOXORUBICIN
}

\author{
N.Yu. Lukianova, ${ }^{1, *}$, A.V. Andriiv ${ }^{2,3}$, V.F. Chekhun ${ }^{1}$ \\ ${ }^{1}$ R.E. Kavetsky Institute of Experimental Pathology, Oncology and Radiobiology, NAS of Ukraine, Kyiv 03022, Ukraine \\ ${ }^{2}$ Ivano-Frankivsk Regional Clinical Cancer Center, Ivano-Frankivsk 76018, Ukraine \\ ${ }^{3}$ Ivano-Frankivsk National Medical University, Ivano-Frankivsk 76018, Ukraine
}

\begin{abstract}
Aim: To investigate the relationship of sodium/iodide symporter (NIS) expression with molecular phenotype of highly and low malignant cell lines of human breast cancer (BC) with different sensitivity to doxorubicin (Dox). Materials and Methods: The cell lines used in the analysis included T47D, MCF-7, MDA-MB-231, MDA-MB-468, and MCF/Dox. NIS expression was studied by immunocytochemical method. Results: The strongest iodine symporter expression $(248 \pm 1.9 ; 272 \pm 3.2$ and $289 \pm 2.8$ points, respectively) were found in cells of highly malignant cell lines - MDA-MB-231, MDA-MB-468, and MCF-7/Dox. NIS expression was significantly weaker ( $<120$ points) in two BC cell lines of low malignancy (MCF-7 and T47D). In addition, the reduced sensitivity to Dox is associated with elevation of NIS expression in both high and low malignant cells. We have demonstrated correlations between NIS levels and certain indices of $\mathrm{BC}$ malignancy, namely proliferative activity $(r=0.51)$, receptor status (estrogen receptor; $r=-0.47$; and progesteron receptor; $r=-0.47)$ and invasiveness $(r=0.46)$. Conclusions: Our data evidence that NIS expression level correlates with BC cells indices of malignancy and their sensitivity to Dox. The results obtained suggest the necessity for further studies of NIS expression in $\mathrm{BC}$ patients aimed at prognosing disease course and monitoring treatment efficacy with anthracyclines.
\end{abstract}

Key Words: sodium/iodide symporter, breast cancer, malignancy, sensitivity to doxorubicin.

Recent studies in breast cancer (BC) indicate substantial variability of morphological variants and molecular profile as well as disease course and response to treatment $[1,2]$. High heterogeneity and pathogenetic diversity of BC make crucial their molecular characterization based on new biological markers [3]. The special attention should be paid to the studies of the role of iodine metabolism disturbances in BC occurrence and progression [4]. The problem of the possible linkage between the impairments of iodine and the $\mathrm{BC}$ occurrence has been discussed repeatedly over many decades, and still remains controversial [5]. Single clinical observations showed that the $B C$ incidence is very low in those regions where endemic goiter is rare.

Sodium/iodide symporter (NIS) is a glycoprotein that is integrated into the basolateral cell surface; it contains 13 transmembrane domains, and is essential component for the thyroid hormones biosynthesis [6]. It is noteworthy, that NIS is able to function as iodine transporter only under conditions of its membrane localization. When the protein translocates from membrane to cytoplasm, which is typical for certain pathological conditions, it loses its functional activity and does not provide iodine absorption by cells from microvasculature [7]. It is known that functional NIS activity depends on various factors: thyroid stimulating hormones, sex hormones, cytokines, transcriptional and growth factors etc. The majority of research is devoted to the NIS activity studies in differentiated

Submitted: August 20, 2016.

${ }^{\star}$ Correspondence: E-mail: lu_na@rambler.ru

Abbreviations used: BC - breast cancer; Dox - doxorubicin;

NIS - sodium/iodide symporter. thyroid carcinoma. Recently, NIS was detected in the cells of hormone-dependent tumors, including prostate and BC. According to the literature data the NIS expression is observed in more than $50 \%$ of malignant breast tumors [8]. There are some papers on correlation between NIS transcriptional activity, tumor receptor status and expression of epidermal growth factor receptor with tyrosine kinase activity. However, the specific evidence of this relationship is absent, and the NIS expression in BC cells with varying sensitivity to anthracycline cytotoxic drugs remains unclear.

The aim - to investigate the relationship of NIS expression with molecular phenotype features of human $\mathrm{BC}$ cells and to clarify participation of this protein in the determination of sensitivity to doxorubicin (Dox).

\section{MATERIALS AND METHODS}

Cell lines and drug treatment. The studies were performed in vitro on 5 human BC cell lines: T47D metastatic breast ductal carcinoma; MDA-MB-231 and MDA-MB-468 - metastatic breast adenocarcinoma; MCF-7 - invasive breast ductal carcinoma; MCF-7/ Dox - its variant, resistant to Dox.

T47D cells were cultured in RPMI- 1640 medium (Sigma, USA) supplemented with bovine insulin $(0.2 \mathrm{U} / \mathrm{ml})$ and $10 \%$ fetal bovine serum (FBS). MCF-7 cells were grown in DMEM (Sigma, USA) supplemented with recombinant human insulin $(0.01 \mathrm{mg} / \mathrm{ml})$ and $10 \%$ FBS. MDA-MB-231 and MDA-MB-468 cells were cultured in Leibovitz's L-15 medium (Sigma, USA) supplemented with $10 \%$ FBS. All cultures were grown on glass cover slips in humidified atmosphere with 5\% $\mathrm{CO}_{2}$ at $37^{\circ} \mathrm{C}$. The resistant variant MCF-7/Dox were originated by growing parental MCF-7 cells with rising Dox concentrations (from 0.1 to $32 \mu \mathrm{g} / \mathrm{ml}$ ), respectively. 
Dox were added twice a week after reseeding. Every 2 months, cell survival rate was analyzed by MTT assay. MCF-7/Dox cells were 10 times as much resistant to the cytotoxic effect of Dox as parental MCF-7 cells. The cell lines were obtained from the Bank of Cell Lines from Human and Animal Tissues of the R.E. Kavetsky Institute of Experimental Pathology, Oncology and Radiobiology (IEPOR) of the National Academy of Sciences of Ukraine.

The high or low malignant phenotype was evaluated taking into account receptor status, proliferation activity and invasive properties [9]. MDA-MB-231, MDAMB-468 and MCF-7/Dox cells were considered highly malignant (absence of steroid hormone receptors, high invasive potential and low adhesive properties). T47D and MCF-7 cells were considered low malignant (high expression of estrogen and progesterone receptors, low invasive activity).

The sensitivity to Dox of explored cell lines was measured by $I_{30}$ and $I_{50}$. For assessment of NIS expression changes caused by Dox in studied cell lines, the cells were incubated with the cytostatic at doses that corresponded to $\mathrm{IC}_{30}$.

Immunocytochemical assay. The cells were fixed on cover slips (in triplicate for each sample) in ice-cold methanol:acetone $(1: 1)$ at $-20{ }^{\circ} \mathrm{C}$ for 120 min and incubated with $1 \%$ bovine serum albumin solution for $20 \mathrm{~min}$. For immunocytochemical assay primary anti-NIS monoclonal antibody (Clone FP5A) (1:150) (Thermo Scientific, USA) was used. UltraVision LP Detection System (Lab Vision, Thermo Scientific, USA) and DAB Quanto (Thermo Scientific) were used according to the instructions of the manufacturers. When immunocytochemical reaction was completed, the cells were stained with haematoxylin by Mayer and placed in Faramount Aqueous Mounting Medium (DakoCytomation, Denmark). Results were analyzed by light microscopy ( $\times 1000$, oil immersion) with the use of classical $\mathrm{H}$-Score method:

$$
S=1 \cdot N 1^{+}+2 \cdot N 2^{+}+3 \cdot N 3^{+}
$$

where $\mathrm{S}-\ll \mathrm{H}$-Score» index, $\mathrm{N} 1^{+}, \mathrm{N} 2^{+}$and $\mathrm{N}^{+}-$ number of cells with low, medium or high marker expression [10]. The level of studied markers expression was assigned as follows: low — from 0 to $100 \mathrm{H}$-score points, medium - from 100 to $200 \mathrm{H}$-score points, and high - from 200 to $300 \mathrm{H}$-score points.

Statistical analysis. STATISTICA 6.0 computer program (StatSoft Inc., USA) was used for statistical processing of the obtained results. Differences between the average values were compared with use of Student's t-test; correlation analysis was performed using Pearson correlation coefficient. Differences were considered as significant with the probability not less than $95 \%(p<0.05)$.

\section{RESULTS AND DISCUSSION}

As seen from the data presented in Table 1, two of three highly malignant cell lines used in the study, namely MDA-MB-468 and MCF-7/Dox high were Dox resistant. Two low malignant cell lines (T47D and MCF-7) and one highly malignant cell line (MDA-MB-231) were sensitive to Dox.

Table 1. The level of sensitivity of BC cells to Dox

\begin{tabular}{lcc}
\hline \multicolumn{1}{c}{ Cell lines and their } & \multicolumn{2}{c}{ Inhibitory concentration of Dox } \\
\cline { 2 - 3 } \multicolumn{1}{c}{ malignancy } & IC30 & IC50 \\
\hline T47D low $(n=3)$ & 0.9 & 1.5 \\
MCF-7 low $(n=3)$ & 1.5 & 2.5 \\
MDA-MB-231 high $(n=3)$ & 1.8 & 3.0 \\
MDA-MB-468 high $(n=3)$ & 6.0 & 10.0 \\
MCF-7/Dox high $(n=3)$ & 15.0 & 25.0 \\
\hline
\end{tabular}

Immunocytochemical analysis revealed different NIS expression in studied cells lines. The highest values of iodine symporter expression ( $248 \pm 1.9 ; 272 \pm 3.2$ and $289 \pm 2.8$ points, respectively) were found in highly malignant cell lines MDA-MB-231, MDA-MB-468 and MCF-7/ Dox (Table 2). NIS expression was significantly weaker (<120 points) in two low malignant cell lines (MCF-7 and T47D). In Dox-resistant variant of MCF-7 cells (MCF-7/ Dox), NIS expression was 2.5 times as much as in parental MCF-7 cell line (see Table 2 ).

Table 2. NIS expression in BC cells of different malignancy and sensitivity to Dox

\begin{tabular}{lccc}
\hline \multicolumn{1}{c}{ Cell line } & $\begin{array}{c}\text { Malignancy } \\
\text { features }\end{array}$ & $\begin{array}{c}\text { Sensitivity } \\
\text { to Dox }\end{array}$ & $\begin{array}{c}\text { NIS expression level } \\
\text { (H-score, points) }\end{array}$ \\
\hline T47D & Low & High & $73.0 \pm 2.0$ \\
MCF-7 & Low & High & $115.0 \pm 1.9$ \\
MDA-MB-231 & High & High & $248.0 \pm 2.6^{\star}$ \\
MDA-MB-468 & High & Middle & $272.0 \pm 2.5^{\star}$ \\
MCF-7/Dox & High & Low & $289.0 \pm 2.8^{*}$, \\
\hline
\end{tabular}

Note: ${ }^{\star} p<0.05$ in comparison with low malignant cells; ${ }^{*} \mathrm{p}<0.05$ in comparison with cells of parental MCF-7 line.

Since we know that NIS is able to transport iodine only when it is expressed on cells membranes [11, 12], we attempted to analyze NIS localization in studied cells lines. In low malignant cell (T47D and MCF-7), NIS expressed both on membrane and in cytoplasm, but in highly malignant cell lines, the cytoplasmic reaction with antibodies against this protein prevailed (Fig. 1). It should be noted that in MCF-7/Dox cells NIS relocalized to cytoplasm as compared to the parental MCF-7 cell line (see Fig. 1). Therefore, in highly malignant cell lines, Dox resistance is accompanied with NIS relocalization.

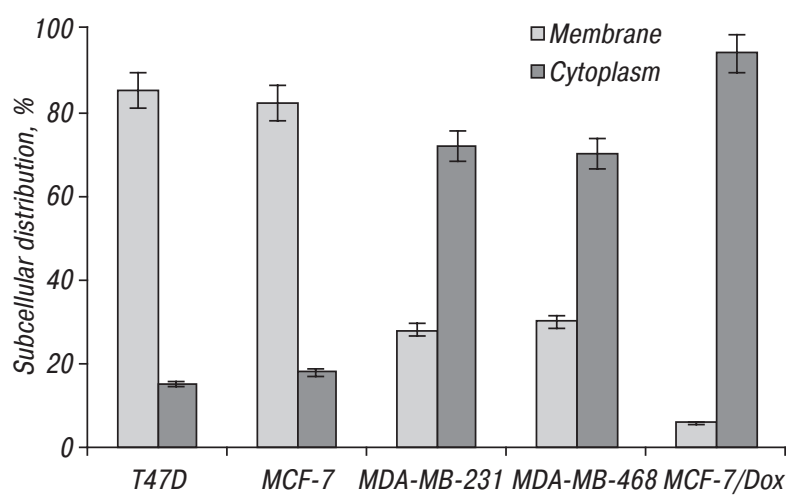

Fig. 1. Subcellular distribution of NIS in BC cells of different malignancy and sensitivity to Dox

The analysis of correlations allowed us to determine the relations of NIS expression with some indices of BC malignancy. Increase in NIS expression was associated with the lack of steroid hormones receptors in highly malignant cells and in cells with phenotype of chemoresistance to Dox (Table 3). The 
direct correlation between NIS expression and indices of proliferative activity in cells of low malignancy was observed (see Table 3). We proved the association of NIS level with invasive properties of low malignant cells and MCF-7/Dox cells (see Table 3). The above data confirm the NIS participation in the formation of $\mathrm{BC}$ cells molecular phenotype.

Table 3. Correlation between NIS expression and indices of malignancy of $B C$ cells

\begin{tabular}{lccc}
\hline \multirow{2}{*}{ Indices } & \multicolumn{3}{c}{ Correlation coefficients } \\
\cline { 2 - 4 } & Low malignancy & High malignancy & Resistance to Dox \\
\hline NIS/estrogen receptors & $-0.47^{*}$ & $-0.49^{\star}$ & $-0.61^{*}$ \\
NIS/progesteron & $-0.43^{*}$ & $-0.49^{\star}$ & $-0.58^{*}$ \\
receptors & $0.51^{\star}$ & 0.25 & 0.22 \\
NIS/Ki-67 & $0.46^{*}$ & 0.19 & $0.54^{\star}$ \\
NIS/invasiveness & & &
\end{tabular}

Note: ${ }^{*} \mathrm{p}<0.05$

In cell cultures supplementation with Dox, marked reduction in NIS expression was observed in T47D and MCF- 7 cell lines (by 30 and $42 \%$, respectively), that are characterized by high sensitivity to this cytostatic drug and in MDA-MB-231 line (by 19.3\%) (Fig. 2). Supplementation with Dox did not affect NIS level in Dox-resistant MDA-MB 468 and MCF-7/Dox cell lines. These data strongly suggest the role of NIS in realization of cytostatics effects of Dox.

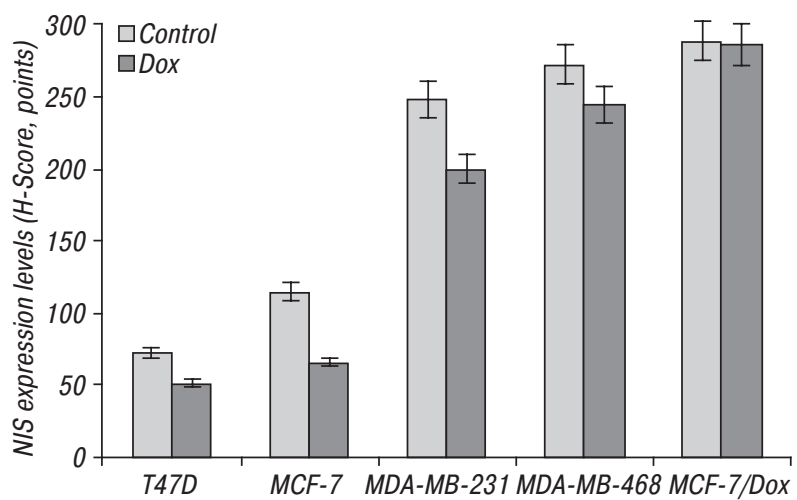

Fig. 2. NIS expression shifts in human $B C$ cells caused by Dox

We found the correlations between NIS expression and malignant phenotype as well Dox resistance in human BC cell lines. The highest NIS expression was demonstrated in high malignant cell lines resistant to Dox. Our results coincide with published data on correlations between NIS levels and certain indices of $\mathrm{BC}$ malignancy, namely proliferative activity, receptor status and invasiveness [13-15]. The data obtained indicate that elevated NIS level and its subcellular relocalization are associated with the lack expression of steroid hormone receptors, high proliferative activity and invasiveness of BC cells. These features may be associated with the reduced iodine absorption by highly malignant cells as the consequence of altered NIS functional activity [16]. The detected relationship between NIS level and sensitivity of human BC cells to Dox allows one to suggest NIS participation in the mechanisms of realization of Dox cytostatic effects. The significant shifts of NIS expression that we found in cells with Dox-resistant phenotype are probably due to the MDR1 gene activation $[17,18]$.
To sum up, our data demonstrate that NIS expression level correlates with BC cells indices of malignancy as well Dox resistance in human BC cell lines. Further studies of NIS expression in BC patients seem to be advantageous for predicting the disease course and monitoring treatment efficacy with antracyclines.

\section{REFERENCES}

1. Yersal O, Barutca S. Biological subtypes of breast cancer: prognostic and therapeutic implications. World J Clin Oncol 2014; 5: 412-24.

2. Malhotra GK, Zhao X, Band H, Band V. Histological, molecular and functional subtypes of breast cancers. Cancer Biol Ther 2010; 10: 955-60.

3. Rivenbark AG, O'Connor SM, Coleman WB. Molecular and cellular heterogeneity in breast cancer: challenges for personalized medicine. Am J Pathol 2013; 183: 1113-24.

4. Ahad F, Ganie SA. Iodine, iodine metabolism and iodine deficiency disorders revisited. Indian J Endocrinol Metab 2010; 14: 13-7.

5. Ditsch N, Liebhardt S, Koch F. Thyroid function in breast cancer patients. Anticancer Res 2010; 30: 1713-7.

6. Portulano C, Paroder-Belenitsky M, Carrasco N. The$\mathrm{Na}+/ \mathrm{I}-$ symporter (NIS): mechanism and medical impact. Endocr Rev 2014; 35: 106-49.

7. Renier C, Yao C, Goris M, et al. Endogenous NIS expression in triple-negative breast cancers. Ann Surg Oncol 2009; 16: 962-8.

8. Hansen RK, Bissell MJ. Tissue archistructure and breast cancer: the role of extracellular matrix and steroid hormones. Endoc Relat Cancer 2000; 7: 95-113.

9. Chekhun VF, Zalutskii IV, Naleskina LA, et al. Modifying effects of lactoferrin in vitro on molecular phenotype of human breast cancer cells. Exp Oncol 2015; 37: 181-6.

10. McClelland RA, Wilson D, Leake R. A multicentre study into the reliability of steroid receptor immunocytochemical assay quantification. Eur J Cancer 1991; 27: 711-5.

11. Chung JK. Sodium iodide symporter: its role in nuclear medicine. J Nucl Med 2002; 43: 1188-200.

12. Hellevik A, Asvold B, Bjoro T, et al. Thyroid function and cancer risk: a prospective population study. Cancer Epidemiol Biomarkers Prev 2009; 18: 570-4.

13. Lavarone E, Puppin C, Passon N, et al. The PARP inhibitor PJ34 modifies proliferation, NIS expression and epigenetic marks in thyroid cancer cell lines. Mol Cell Endocrinol 2013; 365: 1-10.

14. Luidens M, Mousa S, Davis E, et al. Thyroid hormone and angiogenesis. Vascul Pharmacol 2010; 52: 142-5.

15. Lacoste C, Herve J, Bou Nader M, et al. Iodide transporter NIS regulates cancer cell motility and invasiveness by interacting with the Rho guanine nucleotide exchange factor LARG. Cancer Res 2012; 72: 5505-15.

16. Renier C, Yao C, Goris M, et al. Endogenous NIS expression in triple-negative breast cancers. Ann Surg Oncol 2009; 16: 962-8.

17. Ahn SJ, Jeon YH, Lee YJ, et al. Enhanced anti-tumor effects of combined MDR1 RNA interference and human sodium/iodide symporter (NIS) radioiodine gene therapy using an adenoviral system in a colon cancer model. Cancer Gene Ther 2010; 17: 492-500.

18. Micali S, Bulotta S, Puppin C, et al. Sodium iodide symporter (NIS) in extrathyroidal malignancies: focus on breast and urological cancer. BMC Cancer 2014; 14: 303. 